\title{
The use of positive pressure ventilation fans during firefighting operations in underground stations: an experimental study
}

\author{
K. Lambert ${ }^{1,3}$, S. Welch ${ }^{2}$ and B. Merci $^{3}$ \\ ${ }^{1}$ Brussels Fire Department (Belgium) \\ ${ }^{2}$ The University of Edinburgh (UK) \\ ${ }^{3}$ Ghent University - UGent, Department of Flow, Heat and Combustion Mechanics, Ghent \\ (Belgium)
}

\begin{abstract}
Positive pressure ventilation (PPV) fans are widely used by the fire service during firefighting operations in buildings. Fans are positioned to create a flow through the enclosure. This flow can remove the smoke after the fire or affect the direction of the smoke to support firefighting operations. In subway stations, it is less common to use PPV fans. Here, 106 full-scale tests with up to four fans have been performed in a training building that represents a subway station. The fans were used as extraction fans. The generated flow through the subway station has been measured. The critical velocity for a hypothetical tunnel $(\mathrm{W} \times \mathrm{H}: 3.17 \times 4.15 \mathrm{~m})$ attached to the subway station has been calculated as $2.37 \mathrm{~m} / \mathrm{s}$. Reaching the critical velocity has been used as criterion for 'success'. All combinations with four fans exceed this velocity, supporting the idea that the fans could be used to facilitate a firefighting operation. The location of the fans was varied. Combinations with three fans on the platform and one at the top of the staircase performed better than combinations with two fans on the platform, one on the landing and one at the top of the staircase. There is an optimum value for the distance between the fans on the platform and the first step of the staircase. This value depends on the angle of inclination of the fans. The fans were not capable of creating a flow that exceeded the critical velocity in the station itself $(\mathrm{L} \times \mathrm{W} \times \mathrm{H}: 60 \times 7.15 \times 4.53 \mathrm{~m})$. However, a velocity of $2.40 \mathrm{~m} / \mathrm{s}$ corresponds to a flow rate that will limit the backlayering distance in the station to $15 \mathrm{~m}$. This was only achieved by tests with four fans (three on the platform and one at the top of the staircase).
\end{abstract}

Keywords: Positive pressure ventilation, PPV, fire service intervention, full-scale experiments, subway stations

\section{Nomenclature}

$c_{p} \quad$ Specific heat of air $(\mathrm{kJ} / \mathrm{kg} . \mathrm{K})$

$\varepsilon \quad$ Reduction in critical velocity due to an

obstruction

$F \quad$ Flow rate $\left(\mathrm{m}^{3} / \mathrm{s}\right)$

g Gravitational acceleration $\left(\mathrm{m} / \mathrm{s}^{2}\right)$

$H \quad$ Tunnel height

$\bar{H} \quad$ Hydraulic tunnel height

$L_{b} \quad$ Backlayering distance $(\mathrm{m})$ $\rho_{0} \quad$ Ambient density $\left(\mathrm{kg} / \mathrm{m}^{3}\right)$

$Q \quad$ Heat release rate $(\mathrm{kW})$

$Q^{*} \quad$ Dimensionless heat release rate

$T_{0} \quad$ Ambient temperature (K)

$V_{c r} \quad$ Critical velocity $(\mathrm{m} / \mathrm{s})$

$V_{c t r} \quad$ Critical velocity in the obstructed tunnel (m/s)

$V_{c r}^{*} \quad$ Dimensionless critical velocity

$V^{*} \quad$ Dimensionless ventilation velocity 


\section{Introduction}

Positive pressure ventilation is a tactic used by the fire service in order to remove smoke, heat and other combustion products from a building during or after a fire [1]. In order to do so, portable fans are placed at inlet openings while outlet openings are created as required. The fans generate a flow through the building. This flow will, in turn, remove the smoke. In the past, several research projects have been undertaken to evaluate the effectiveness of PPV in different circumstances [2]-[11].

In the present study, we focus on the use of PPV fans in the context of underground stations. In fact, the fans are used as extraction fans, so it could be called 'negative pressure ventilation'.

Le Corré [5] performed a study on the use of PPV fans in the Paris underground. He suggested using the escalator shafts as outlet for the mobile ventilation system. In a previous testing programme, the usage of combustion engine driven fans had led to unacceptably high CO concentrations stemming from the fan exhaust. Therefore, Le Corré decided to use electric fans in a new series of tests.

The principle that Le Corré describes, was also used during this experimental campaign. A staircase of a training building was used as an outlet for a flow, driven by electric fans, positioned on the platform.

In the case of a subway car fire in the tunnel, the fans on the platform could create a flow in the tunnel. The fans create a forward momentum. Due to the moving air, there is air entrainment in the cone, created by the fans. The fans create an air movement that leads to a pressure difference between the inlet opening and the outlet opening.

Two different, hypothetical situations are evaluated:

1) A fire in the tunnel

2) A fire in the subway station

In order to evaluate this tactic, a scenario was studied with a tunnel attached to the training building. The critical velocity, needed to prevent smoke backlayering in the tunnel in the case of a hypothetical fire, was determined. The velocity that the fans would be able to generate in that tunnel, was subsequently compared to that critical velocity.

The goal of this series of experiments is to evaluate the effectiveness of PPV fans, operating as extraction fans, in a subway station.

\section{Experimental set-up}

\subsection{The building}

Frankfurt fire department has a state-of-the-art fire academy at their disposal. A small underground station has been built to provide realistic training. The station has only one track and only one staircase and is not connected to a tunnel network (see Figure 1). In a 
real subway station, more staircases will be available. This is important for this study because we report on PPV experiments that use the staircase as outlet. In a fire situation at a real subway station, the other staircases and escalators would be used by the public to evacuate. One of the other staircases, preferably opposite to the one used to evacuate smoke, would be used by the firefighters to attack the fire. In the case of a fire in a tunnel, the firefighters could even use the staircase at the adjacent station to enter the tunnel and attack the fire from a smoke-free environment. This paper limits itself to the evaluation of the flow generated by the PPV fans to evaluate this tactic. Therefore, the absence of another staircase is not considered a problem.

The underground station is $60 \mathrm{~m}$ long. It has only one floor, of height $4.53 \mathrm{~m}$. The building is $6.35 \mathrm{~m}$ wide. There is a $2.20 \mathrm{~m}$ wide staircase, which provides the main access to the station and leads to the only exit door. This door is $1.93 \mathrm{~m}$ wide and $2.47 \mathrm{~m}$ high.

At the bottom of the staircase, the opening from the platform to the staircase is created by the $4^{\text {th }}$ step and the ceiling (See Figure 1). That opening is $2.20 \mathrm{~m}$ wide and $3.73 \mathrm{~m}$ high. There is an entrance for the underground trains of dimensions $3.17 \mathrm{~m}$ wide and 4.15 $\mathrm{m}$ high.

The station is actually a building for training, and as such there is no tunnel attached to it. However, for the purpose of this study one could assume that the station is part of a underground network and there is a tunnel attached to the station. To analyse the generated flows, the assumption is made that a tunnel is attached to the entrance for the underground train. The interior dimensions of that tunnel were taken as $3.17 \mathrm{~m}$ wide and $4.15 \mathrm{~m}$ high, the dimensions of the entrance for the subway cars.

During all the experiments one fan was positioned at the top of the staircase, inside the structure, blowing towards the outside. The other fans were placed on the platform, blowing towards the staircase. By doing so, the door opening at the top of the stairs acted as outlet opening while the opening for the railcars served as the inlet opening. The ratio between the inlet and the outlet opening surface area is 2.76 .

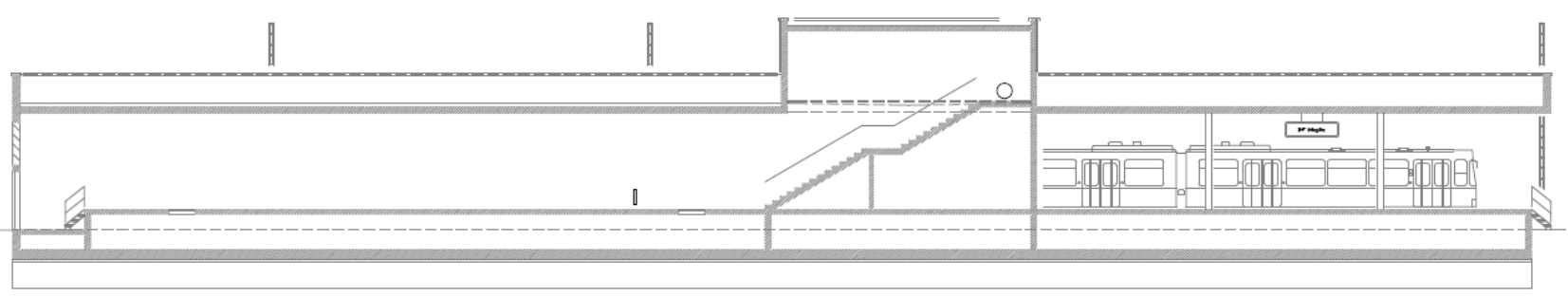




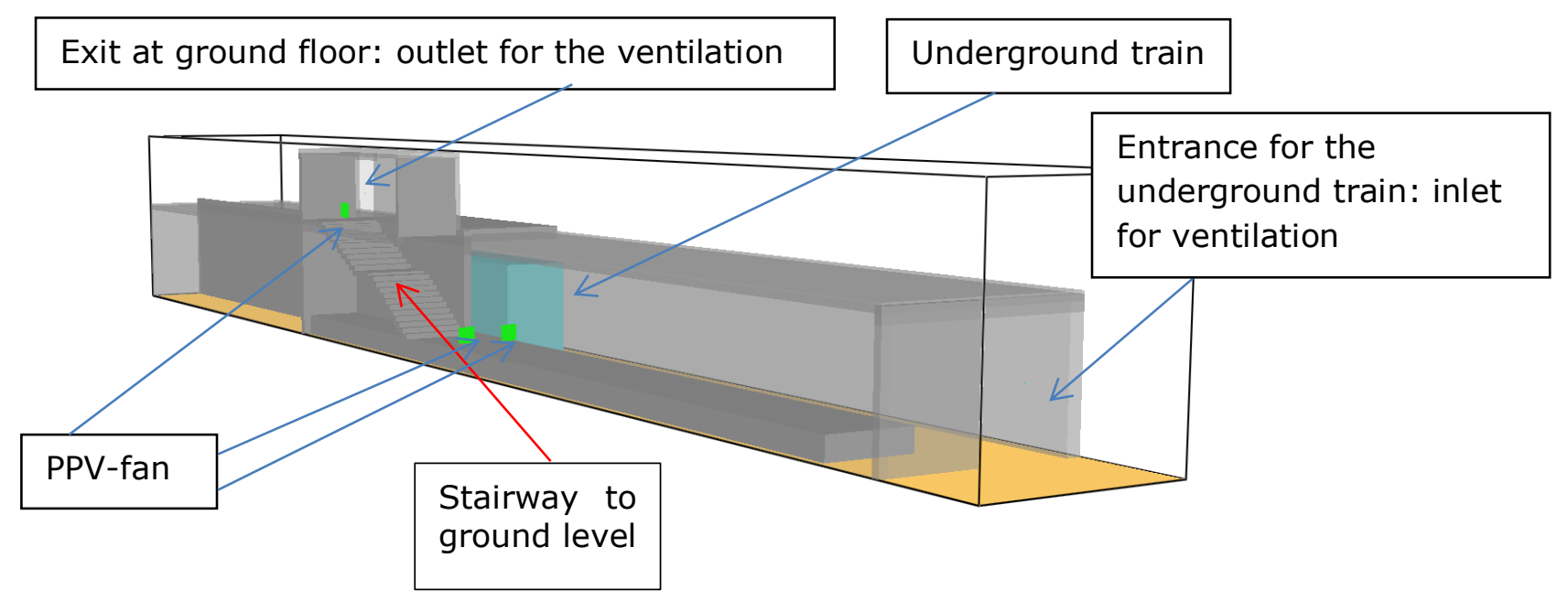

Figure 1 Top: Cross section of the underground station at the Frankfurt fire academy. Bottom: sketch in perspective.

\subsection{Measuring equipment}

In order to measure the flows generated by the fans, a system was put in place to measure the air velocities going through the entry opening of the underground trains. The system consisted of 9 bidirectional probes, 9 pressure transducers and a data logging system. In order to evaluate ambient weather conditions a weather station was used.

\subsubsection{Bidirectional probes}

In order to do the measurements, a grid with bidirectional velocity probes was installed. The probe described by McCaffrey and Heskestad [13] was used. The diameter of the probe was $25.4 \mathrm{~mm}$, rather than the more often used $12.7 \mathrm{~mm}$, in order to increase the Reynolds number of the flow through the probe. By doing so, the value of the calibration constant $k_{p}$ is less prone to variations at low velocities. The density term required for the velocity calculation is taken from the ambient temperature measurement.

The entry opening for the underground trains was used as a location for the measurements. The flow going through this opening was ascertained by multiplying the average velocity by the surface area of the opening. The opening was divided into 9 identical rectangular parts as shown in Figure 2. A bidirectional probe was placed in the middle of each rectangular part. This

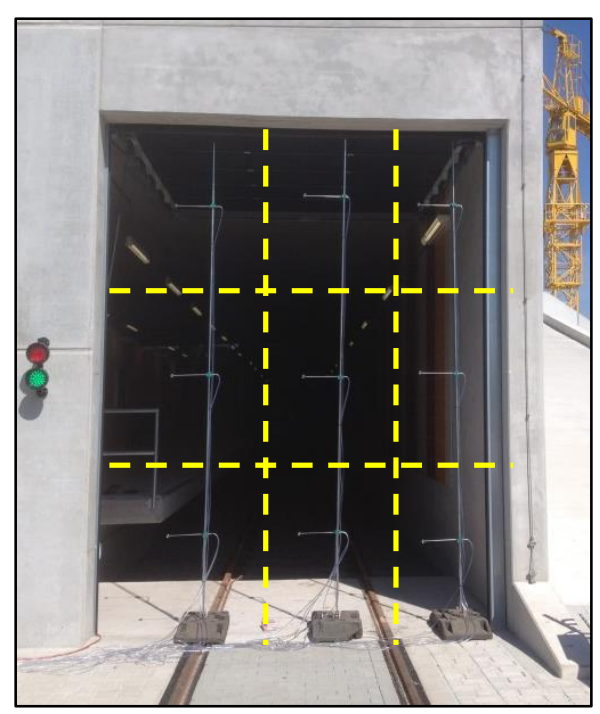

Figure 2 The opening of subway station is divided in 9 rectangles. A bidirectional probe is positioned in the middle of every rectangle. approach takes into account the fact that there will be an effect of the boundaries of the opening on the local velocity.

A similar approach was used by Lambert et al. for PPV experiments in a staircase [11]. 


\subsubsection{Pressure transducer}

The probes were connected to differential pressure transducers. The transducers were of the type LP 1000. The range of the transducers was from - $25 \mathrm{~Pa}$ to $+25 \mathrm{~Pa}$. The accuracy was $0.25 \%$ of the full scale. The output was a Volt signal within the range 0 to 10 Volt.

\subsection{Experimental procedure}

During all of the 106 tests, the same experimental procedure was used:

1) The fans were placed in the correct position.

2) The velocity generated by the wind conditions was measured during 60 seconds. The voltage generated by the pressure transducers was recorded every 3 seconds.

3) The fans were started.

4) The generated velocity was measured during 300 seconds. The voltage generated by the pressure transducers was recorded every 3 seconds.

5) The fans were stopped.

The data were processed as follows:

1) The 60 seconds of measurements of the wind conditions were time-averaged for every experiment. This led to a base value for the wind conditions prior to each experiment.

2) The measured voltage during the 300 seconds was reduced by the base value for every measurement. By doing so the reduced voltage represents the differential pressures generated by the fans and the effect of the wind is removed. The underlying assumption is that the 60 seconds prior to the experiment itself are representative for the 300 seconds of measurements. Since there were no strong wind gusts during the days of measurement, this is a valid assumption.

3) The reduced voltages were transformed into differential pressures. The calculation procedure of McCaffrey and Heskestad [13] was used to calculate the velocities corresponding to the differential pressures.

4) The velocities were multiplied by the area of the rectangles in Figure 2 to end up with a flow rate generated by the fans. These are the values reported below in the section 'Results'.

It should be noted that this approach does not take into account the fact that there are flow losses close to the sides of the opening. This study is intended to serve fire service interventions, where the fans will not be positioned in a very accurate manner during firefighting (from a scientific research point of view). As such, the effect of the deviation between the actual position of the fan(s) and the exact position of the fan(s) in the paper at hand, can be larger than the effect of an error caused by the measuring method. Therefore, we consider the measuring method acceptable for the sake of our study. 


\subsection{Fans}

In the experiments, two types of electrically powered fans were used.

The Leader 'car park' fan can generate a flow of $29 \mathrm{~m}^{3} / \mathrm{s}\left(104,000 \mathrm{~m}^{3} / \mathrm{h}\right)$ in the open air, using an electrical engine of $17.3 \mathrm{~kW}$ [22]. This type of fan will be indicated as 'Fan $A^{\prime}$ throughout the remainder of the paper.

The Leader 'ESV 280 ' can generate a flow of $24 \mathrm{~m}^{3} / \mathrm{s}\left(87,500 \mathrm{~m}^{3} / \mathrm{h}\right)$ in the open air, using an electrical engine of $11.4 \mathrm{~kW}$ [22]. This type of fan will be indicated as 'Fan B'.

Both fans have a standard vertical inclination of $10^{\circ}$. This can be altered within the range $10^{\circ}-18^{\circ}$. In the experiments, the angles of $10^{\circ}$ and $18^{\circ}$ were used.

Both fans can be operated by a single firefighter as long as there are no stairs to be passed. When the fan has to be carried on the stairs, experience during the experiments showed that this can be done easily by three firefighters.

\subsection{Criterion for success}

A criterion for success was defined for two situations: fire in the tunnel and fire in the station itself.

\subsubsection{For the tunnel}

The objective is to create a longitudinal flow in the tunnel with a velocity strong enough to exceed the critical velocity $\left(v_{c r}\right)$ in the tunnel leading towards the subway station, to prevent the smoke from flowing upstream [14],[15], [16].

Wu and Bakar [15] used the tunnel mean hydraulic diameter or the hydraulic tunnel height, $\bar{H}$, as the characteristic length in the dimensionless analysis of the critical velocity. The hydraulic tunnel height is equal to the ratio of four times the section of the tunnel to the wetted perimeter. They defined two dimensionless variables, namely the dimensionless heat release rate $Q^{*}$ and the dimensionless critical ventilation velocity $V_{c r}^{*}$ :

$$
\begin{aligned}
Q^{*} & =\frac{Q}{\rho_{0} c_{p} T_{0} g^{\frac{1}{2}} \bar{H}^{\frac{5}{2}}} \\
V_{c r}^{*} & =\frac{V_{c r}}{\sqrt{g \bar{H}}}
\end{aligned}
$$

They found that the critical velocity becomes independent of the heat release rate when the heat release rate is sufficiently high, while in fire situations with a low heat release rate, the critical velocity will increase when the heat release rate increases:

$$
\begin{array}{ll}
V_{c r}^{*}=0.40(0.20)^{-1 / 3} Q^{* 1 / 3} & \text { for } Q^{*} \leq 0.2 \\
V_{c r}^{*}=0.40 & \text { for } Q^{*}>0.2
\end{array}
$$


When equation ( 1 ) is used to solve for $Q$, taking $Q^{*}=0.2$, the value of $5.37 \mathrm{MW}$ is found for the set-up at hand.

Using equations (2) and (4) with the size of the entry opening for the railcars $(3.15 \mathrm{~m} \mathrm{x}$ $4.17 \mathrm{~m}, \mathrm{~W} \times \mathrm{H}$ ) as interior dimensions of the tunnel, the value is $\mathrm{V}_{c r}=2.37 \mathrm{~m} / \mathrm{s}$. This corresponds to a flow rate $F=31.2 \mathrm{~m}^{3} / \mathrm{s}$, which has been indicated as a solid red line in the figures below.

A longitudinal ventilation that exceeds this value will be able to prevent backlayering in the case of a fire in the tunnel, regardless its heat release rate. In reality, the fire source will have a blocking effect on the flow. In the case of a major fire, it is likely that a subway car is the fire source. The size of the subway car will thus have an effect on the flow through the tunnel. Li et al. [17] have looked into this. They found that the reduction ratio in critical velocity due to the obstruction, $\varepsilon$, is slightly greater than the ratio of the cross-sectional area of the vehicle in the tunnel to the cross-section of the tunnel itself. This leads to the following equation [17]:

$$
\varepsilon=\frac{V_{c r}-V_{c t r}}{V_{c r}}
$$

In this equation $V_{c}$ represents the critical velocity, while $V_{c t r}$ represents the critical velocity in the obstructed tunnel.

Taking Li's findings into consideration, it means that the value of $2.37 \mathrm{~m} / \mathrm{s}$ will be an overestimation. In the framework of this study, the cross-section of a possible fire source is not known: the fire is hypothetical. As the impact of the dimensions of the burning object is a reduction of the required flow, this is considered a margin of safety in this study. The value of $2.37 \mathrm{~m} / \mathrm{s}$ will be used as the criterion of success for the generated flow in the tunnel.

\subsubsection{For the subway station}

The cross-section of the subway station itself is much larger than the tunnel. This will lead to lower velocities in the station than in the tunnel. When the critical velocity is not achieved, smoke backlayering will occur. The longer the backlayering distance, the harder it gets for firefighters to locate and fight the fire. The Belgian legislation regarding covered car parking buildings uses the concept of backlayering as well [18]. A backlayering distance of $15 \mathrm{~m}$ is considered to be the maximum acceptable in this standard. This means that firefighters can make most of their approach in a smoke-free environment. The last part of the approach to the seat of the fire is in a smoke-filled environment. However, if the smoke-filled environment is $15 \mathrm{~m}$ or less, the fire becomes within the reach of their hose jets as soon as their view is blocked by smoke. The thermal imaging camera (TIC) will then be a helpful tool to locate and fight the fire. A backlayering distance of less than $15 \mathrm{~m}$ will be considered a success.

It is noticed that the criterion for success for the tunnel (i.e., no backlayering) is more strict than the criterion for success in the station (i.e., $15 \mathrm{~m}$ backlayering allowed). This is because the fans are capable of achieving a super-critical flow in the tunnel. This situation presents an advantage for the firefighters since this creates a smoke-free environment 
upstream of the fire. The fans are not capable of achieving a super-critical flow in the station itself. Therefore, it would be unrealistic to require the absence of smoke backlayering from a practical point of view.

The station itself is treated as a large rectangular tunnel here, in order to estimate the backlayering distance. Li et al. [17] provide the following correlations for the backlayering distance in tunnels:

$$
\begin{array}{ll}
\frac{L_{b}}{H}=18.5 \ln \left(0.81 \frac{Q^{* 1 / 3}}{V^{*}}\right) & \text { for } Q^{*} \leq 0.15 \\
\frac{L_{b}}{H}=18.5 \ln \left(\frac{0.43}{V^{*}}\right) & \text { for } Q^{*}>0.15
\end{array}
$$

In Eq. (5) and (6), $V^{*}$ is defined as $V^{*}=\frac{V}{\sqrt{g H}}$, with $V$ the longitudinal velocity in the tunnel, while $Q^{*}$ is defined as $Q^{*}=\frac{Q}{\rho_{c} c_{p} T_{0} g^{1 / 2 H^{5} / 2}}$ (i.e., compared to Eq. (1), the height is used in Eq. (6) and (7)).

They found that the backlayering distance becomes independent of the heat release rate when the heat release rate is sufficiently high, while in fire situations with a low heat release rate, the backlayering distance will increase when the heat release rate increases. The value of 0.15 for $\mathrm{Q}^{*}$ in the station corresponds to a heat release rate of $7.42 \mathrm{MW}$ for the set-up at hand. (The height in the subway station is $4.53 \mathrm{~m}$.)

The height of the building can be substituted into Eq. (6) and Eq. (7). The generated flow rate, measured during the tests, can be converted into an average velocity $V$ that can also be put into the Eq. (6) and Eq. (7). The average velocity is calculated by dividing the flow rate by the net cross-section of the station. Therefore, the cross-section of the station is reduced by the cross-section of the subway car. The dimensions of the subway cars in Frankfurt are $2.65 \times 3.61(\mathrm{~W} \times \mathrm{H})$. It is noted that the assumption of uniform velocity is a strong simplification of reality. Nevertheless, it does provide a first indication with respect to the potential of success of the tactic.

Eq. (7) can be solved for $V$ using $15 \mathrm{~m}$ as the value for the backlayering distance. $15 \mathrm{~m}$ is the maximum acceptable backlayering distance in order to consider the test as a success. For the set-up at hand, the velocity needs to be $2.40 \mathrm{~m} / \mathrm{s}$ or higher to limit the backlayering distance to $15 \mathrm{~m}$.

Using Eq. (6), the heat release rate that corresponds to a backlayering distance of $15 \mathrm{~m}$ can be calculated for the generated flow rate of each of the experiments.

\begin{tabular}{|l|l|c|c|}
\hline \multicolumn{2}{|c|}{ Criteria for success } & V & $F$ \\
\hline Tunnel & Critical velocity $V_{c r}$ & $2.37 \mathrm{~m} / \mathrm{s}$ & $31.2 \mathrm{~m}^{3} / \mathrm{s}$ \\
\hline Station & $\begin{array}{l}\text { Velocity corresponding to } \\
\text { a backlayering length } \mathrm{L}_{b}< \\
15 \mathrm{~m}\end{array}$ & $2.40 \mathrm{~m} / \mathrm{s}$ & $41.3 \mathrm{~m}^{3} / \mathrm{s}$ \\
\hline
\end{tabular}

Table 1 Criteria for success for tunnel and subway station 


\section{Results}

In total 106 full scale experiments were performed, of which 48 were selected for analysis and discussion in this paper. Below, the description is given of the position of the fans used in every experiment, making reference to the number of the according experiment (Table 2).

\begin{tabular}{|c|c|c|c|c|c|c|}
\hline \multirow{2}{*}{$\begin{array}{c}\mathrm{N}^{\circ} \\
\text { experiment }\end{array}$} & \multirow[t]{2}{*}{ type Fan } & \multirow{2}{*}{$\begin{array}{l}\text { distance } \\
(\mathrm{m})\end{array}$} & \multicolumn{3}{|c|}{$\begin{array}{l}\text { Position of the fans on platform or landing } \\
\text { (L) }\end{array}$} & \multirow{2}{*}{$\begin{array}{l}\text { Position } \\
\text { Upstairs }\end{array}$} \\
\hline & & & Fan 1 & Fan 2 & Fan 3 & \\
\hline 29 & $(B+B)+B$ & 1 & $-50 \mathrm{~cm}$ & $+50 \mathrm{~cm}$ & & $40 \mathrm{~cm}$ \\
\hline 30 & $(B+B)+B$ & 3 & $-50 \mathrm{~cm}$ & $+50 \mathrm{~cm}$ & & $40 \mathrm{~cm}$ \\
\hline 31 & $(B+B)+B$ & 5 & $-50 \mathrm{~cm}$ & $+50 \mathrm{~cm}$ & & $40 \mathrm{~cm}$ \\
\hline 32 & $(B+B)+B$ & 7 & $-50 \mathrm{~cm}$ & $+50 \mathrm{~cm}$ & & $40 \mathrm{~cm}$ \\
\hline 33 & $(B+B)+B$ & 9 & $-50 \mathrm{~cm}$ & $+50 \mathrm{~cm}$ & & $40 \mathrm{~cm}$ \\
\hline 34 & $(B+B)+B$ & 1 & $-50 \mathrm{~cm}$ & $+50 \mathrm{~cm}$ & & $90 \mathrm{~cm}$ \\
\hline 35 & $(B+B)+B$ & 3 & $-50 \mathrm{~cm}$ & $+50 \mathrm{~cm}$ & & $90 \mathrm{~cm}$ \\
\hline 36 & $(B+B)+B$ & 5 & $-50 \mathrm{~cm}$ & $+50 \mathrm{~cm}$ & & $90 \mathrm{~cm}$ \\
\hline 37 & $(B+B)+B$ & 7 & $-50 \mathrm{~cm}$ & $+50 \mathrm{~cm}$ & & $90 \mathrm{~cm}$ \\
\hline 38 & $(B+B)+B$ & 9 & $-50 \mathrm{~cm}$ & $+50 \mathrm{~cm}$ & & $90 \mathrm{~cm}$ \\
\hline 56 & $(B+B)+B$ & 3 & $-25 \mathrm{~cm}$ & $+150 \mathrm{~cm}$ & & $40 \mathrm{~cm}$ \\
\hline 57 & $(B+B)+B$ & 3 & $-25 \mathrm{~cm}$ & $+150 \mathrm{~cm}$ & & $90 \mathrm{~cm}$ \\
\hline 58 & $(B+B)+B$ & 3 & $-25 \mathrm{~cm}$ & $+150 \mathrm{~cm}$ & & turn close \\
\hline 59 & $(B+B)+B$ & 3 & $-25 \mathrm{~cm}$ & $+150 \mathrm{~cm}$ & & turn far \\
\hline 60 & $(B+B)+B$ & 5 & $-25 \mathrm{~cm}$ & $+150 \mathrm{~cm}$ & & turn far \\
\hline 61 & $(B+B)+B$ & 7 & $-25 \mathrm{~cm}$ & $+150 \mathrm{~cm}$ & & turn far \\
\hline 62 & $(B+B)+B$ & 9 & $-25 \mathrm{~cm}$ & $+150 \mathrm{~cm}$ & & turn far \\
\hline 72 & $(B+B+B)+A$ & 3 & $-25 \mathrm{~cm}$ & $+150 \mathrm{~cm}$ & $+67 \mathrm{~cm}$ & turn far \\
\hline 73 & $(B+B+B)+A$ & 5 & $-25 \mathrm{~cm}$ & $+150 \mathrm{~cm}$ & $+67 \mathrm{~cm}$ & turn far \\
\hline 74 & $(B+B+B)+A$ & 7 & $-25 \mathrm{~cm}$ & $+150 \mathrm{~cm}$ & $+67 \mathrm{~cm}$ & turn far \\
\hline 75 & $(B+B+B)+A$ & 9 & $-25 \mathrm{~cm}$ & $+150 \mathrm{~cm}$ & $+67 \mathrm{~cm}$ & turn far \\
\hline 77 & $(B+B)+A$ & 5 & $-25 \mathrm{~cm} / 18^{\circ}$ & $+150 \mathrm{~cm} / 18^{\circ}$ & & turn far \\
\hline 79 & $(B+B)+A$ & 3 & $-25 \mathrm{~cm} / 18^{\circ}$ & $+150 \mathrm{~cm} / 18^{\circ}$ & & turn far \\
\hline 81 & $(B+B)+A$ & 7 & $-25 \mathrm{~cm} / 18^{\circ}$ & $+150 \mathrm{~cm} / 18^{\circ}$ & & turn far \\
\hline 83 & $(B+B)+A$ & 9 & $-25 \mathrm{~cm} / 18^{\circ}$ & $+150 \mathrm{~cm} / 18^{\circ}$ & & turn far \\
\hline 97 & $(B+B+B)+A$ & 3 & $-25 \mathrm{~cm} / 18^{\circ}$ & $+150 \mathrm{~cm} / 18^{\circ}$ & $+67 \mathrm{~cm} / 18^{\circ}$ & turn far \\
\hline 98 & $(B+B+B)+A$ & 5 & $-25 \mathrm{~cm} / 18^{\circ}$ & $+150 \mathrm{~cm} / 18^{\circ}$ & $+67 \mathrm{~cm} / 18^{\circ}$ & turn far \\
\hline 99 & $(B+B+B)+A$ & 7 & $-25 \mathrm{~cm} / 18^{\circ}$ & $+150 \mathrm{~cm} / 18^{\circ}$ & $+67 \mathrm{~cm} / 18^{\circ}$ & turn far \\
\hline 100 & $(B+B+B)+A$ & 9 & $-25 \mathrm{~cm} / 18^{\circ}$ & $+150 \mathrm{~cm} / 18^{\circ}$ & $+67 \mathrm{~cm} / 18^{\circ}$ & turn far \\
\hline 68 & $(B+B)+B+A$ & 3 & $-25 \mathrm{~cm}$ & $+150 \mathrm{~cm}$ & $\mathrm{~L}: 0 \mathrm{~cm}$ & turn far \\
\hline 69 & $(B+B)+B+A$ & 5 & $-25 \mathrm{~cm}$ & $+150 \mathrm{~cm}$ & $\mathrm{~L}: 0 \mathrm{~cm}$ & turn far \\
\hline 70 & $(B+B)+B+A$ & 7 & $-25 \mathrm{~cm}$ & $+150 \mathrm{~cm}$ & $\mathrm{~L}: 0 \mathrm{~cm}$ & turn far \\
\hline 71 & $(B+B)+B+A$ & 9 & $-25 \mathrm{~cm}$ & $+150 \mathrm{~cm}$ & $\mathrm{~L}: 0 \mathrm{~cm}$ & turn far \\
\hline 63 & $(B+B)+B$ & 3 & $-25 \mathrm{~cm} / 18^{\circ}$ & $+150 \mathrm{~cm} / 18^{\circ}$ & & turn far \\
\hline 64 & $(B+B)+B$ & 5 & $-25 \mathrm{~cm} / 18^{\circ}$ & $+150 \mathrm{~cm} / 18^{\circ}$ & & turn far \\
\hline 65 & $(B+B)+B$ & 7 & $-25 \mathrm{~cm} / 18^{\circ}$ & $+150 \mathrm{~cm} / 18^{\circ}$ & & turn far \\
\hline
\end{tabular}




\begin{tabular}{|l|l|l|l|l|l|l|}
66 & $(\mathrm{~B}+\mathrm{B})+\mathrm{B}$ & 9 & $-25 \mathrm{~cm} / 18^{\circ}$ & $+150 \mathrm{~cm} / 18^{\circ}$ & & turn far \\
\hline 85 & $(\mathrm{~B}+\mathrm{B})+\mathrm{B}+\mathrm{A}$ & 3 & $-25 \mathrm{~cm}$ & $+150 \mathrm{~cm}$ & $\mathrm{~L}: 0 \mathrm{~cm}$ & turn far \\
\hline 86 & $(\mathrm{~B}+\mathrm{B})+\mathrm{B}+\mathrm{A}$ & 5 & $-25 \mathrm{~cm}$ & $+150 \mathrm{~cm}$ & $\mathrm{~L}: 0 \mathrm{~cm}$ & turn far \\
\hline 87 & $(\mathrm{~B}+\mathrm{B})+\mathrm{B}+\mathrm{A}$ & 7 & $-25 \mathrm{~cm}$ & $+150 \mathrm{~cm}$ & $\mathrm{~L}: 0 \mathrm{~cm}$ & turn far \\
\hline 88 & $(\mathrm{~B}+\mathrm{B})+\mathrm{B}+\mathrm{A}$ & 9 & $-25 \mathrm{~cm}$ & $+150 \mathrm{~cm}$ & $\mathrm{~L}: 0 \mathrm{~cm}$ & turn far \\
\hline 89 & $(\mathrm{~B}+\mathrm{B})+\mathrm{B}+\mathrm{A}$ & 3 & $-25 \mathrm{~cm} / 18^{\circ}$ & $+150 \mathrm{~cm} / 18^{\circ}$ & $\mathrm{L}: 0 \mathrm{~cm} / 18^{\circ}$ & turn far \\
\hline 90 & $(\mathrm{~B}+\mathrm{B})+\mathrm{B}+\mathrm{A}$ & 5 & $-25 \mathrm{~cm} / 18^{\circ}$ & $+150 \mathrm{~cm} / 18^{\circ}$ & $\mathrm{L}: 0 \mathrm{~cm} / 18^{\circ}$ & turn far \\
\hline 91 & $(\mathrm{~B}+\mathrm{B})+\mathrm{B}+\mathrm{A}$ & 7 & $-25 \mathrm{~cm} / 18^{\circ}$ & $+150 \mathrm{~cm} / 18^{\circ}$ & $\mathrm{L}: 0 \mathrm{~cm} / 18^{\circ}$ & turn far \\
\hline 92 & $(\mathrm{~B}+\mathrm{B})+\mathrm{B}+\mathrm{A}$ & 9 & $-25 \mathrm{~cm} / 18^{\circ}$ & $+150 \mathrm{~cm} / 18^{\circ}$ & $\mathrm{L}: 0 \mathrm{~cm} / 18^{\circ}$ & turn far \\
\hline 93 & $(\mathrm{~B}+\mathrm{B}+\mathrm{B})+\mathrm{A}$ & 3 & $-25 \mathrm{~cm}$ & $+150 \mathrm{~cm}$ & $+67 \mathrm{~cm}$ & turn far \\
\hline 94 & $(\mathrm{~B}+\mathrm{B}+\mathrm{B})+\mathrm{A}$ & 5 & $-25 \mathrm{~cm}$ & $+150 \mathrm{~cm}$ & $+67 \mathrm{~cm}$ & turn far \\
\hline 95 & $(\mathrm{~B}+\mathrm{B}+\mathrm{B})+\mathrm{A}$ & 7 & $-25 \mathrm{~cm}$ & $+150 \mathrm{~cm}$ & $+67 \mathrm{~cm}$ & turn far \\
\hline 96 & $(\mathrm{~B}+\mathrm{B}+\mathrm{B})+\mathrm{A}$ & 9 & $-25 \mathrm{~cm}$ & $+150 \mathrm{~cm}$ & $+67 \mathrm{~cm}$ & turn far \\
\hline
\end{tabular}

Table 2 Overview of the 48 experiments discussed in this paper. The number of the experiment is in the first column. The type of fans used is in column 2 . The distance between the fans and the stairs on the platform is given in column 3. (Figure 3 clarifies this distance). Columns 4,5 and 6 indicate the position of the fans with respect to the centre line of the stairs. The indications that are proceeded by " $L$ " indicate fans positioned on the landing of the stairs instead of the platform (see Figure 9). The final column indicates the position of the fan upstairs (see Figure 5).

\subsection{Position of the fans ( 3 fans)}

36 tests were performed with three fans. Several set-ups were used, varying the position of the fan at the top of the staircase and the placement of the fans on the platform.

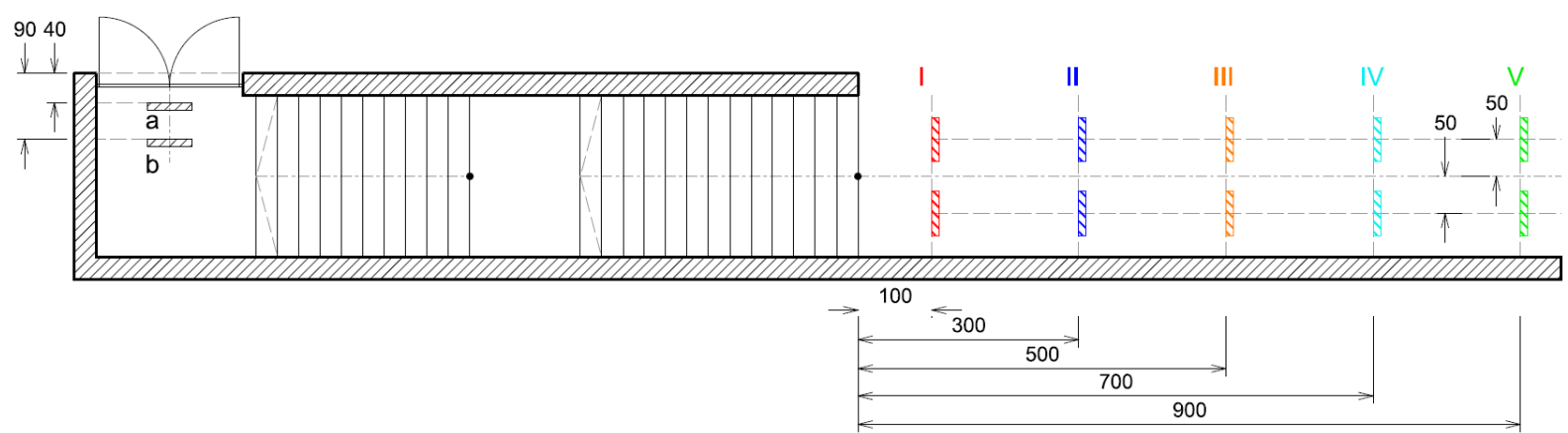

Figure 3 Position of the three fans during tests 29 through 38. Two different positions were used at the top of the staircase. The fan in position 'a' was placed $40 \mathrm{~cm}$ from the exit in tests 29 through 33. Position ' $b$ ' is $90 \mathrm{~cm}$ from the exit. This position was used during tests 34 through 38. These positions were combined with 5 positions ( $\mathrm{I}$ to $\mathrm{V}$ ) on the platform, ranging from $1 \mathrm{~m}$ to $9 \mathrm{~m}$ from the stairs. This combination leads to 10 experiments.

Figure 4 shows the results of a first series of 10 tests with three type $B$ fans as set up in Figure 3. All fans had an inclination of $10^{\circ}$. Two fans were positioned on the platform with reference to the centre line of the stairs $(-50 \mathrm{~cm}$ and $+50 \mathrm{~cm})$. Both fans were placed such that their axis was parallel to the centre line of the stairs. Their distance to the stairs varied from $1 \mathrm{~m}$ to $9 \mathrm{~m}$ with a 2-metre interval. The fan at the top of the staircase was placed on the centre line of the exit opening. The distance from the fan to the door was $40 \mathrm{~cm}$ during the tests 29 through 33 and $90 \mathrm{~cm}$ for the tests 34 through 38 .

In general, (with one outlier for the distance of $5 \mathrm{~m}$ ), the flow rates are higher (5 to $11 \%$ ) with the fan at the top of the staircase at $90 \mathrm{~cm}$ from the door, compared to $40 \mathrm{~cm}$. 
Probably the pushing of the flow through the exit door is more effective because the flow from the fan covers a larger part of the exit opening. Differences are not large, though.

A decrease in flow rate is observed if the fan on the platform is too close to the stairs. This leads to increased pressure losses for the flow, hitting the stairs too fiercely. An optimum is found at a distance around $7 \mathrm{~m}$. This is explained as follows: The diameter of the cone of air that is generated by the fan increases with increasing distance from the fan. The spread rate of the cone is $15^{\circ}$ [22]. At a distance of $7 \mathrm{~m}$ the diameter of the cone is 3.71 $\mathrm{m}$. This corresponds to the height of the opening, which is $3.73 \mathrm{~m}$. At a distance of $9 \mathrm{~m}$, the diameter of the cone would be $4.60 \mathrm{~m}$. This causes the flow to hit the ceiling before entering the staircase. This leads to increased pressure losses. Another reason why the experiments with fans at a distance of $9 \mathrm{~m}$ generate a lower flow rate is that part of the flow will end up beside the staircase (e.g. between the wall and the subway train shown in Figure 1). That part of the flow generated by the fans will not be effective. All the experiments with fans at a distance of $3 \mathrm{~m}$ or larger generate a flow that exceeds the flow rate corresponding to the critical velocity.

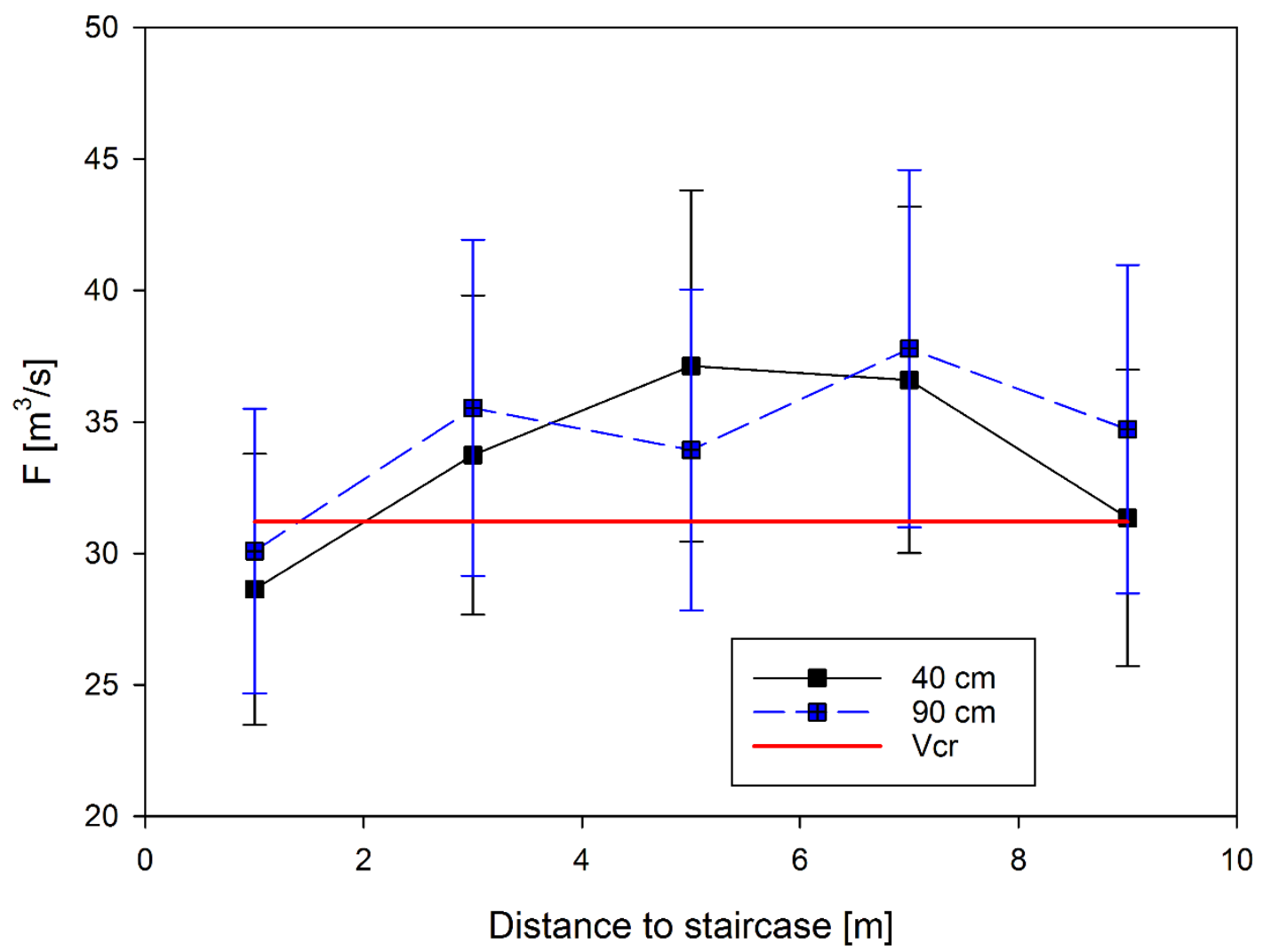

Figure 4 Position of the fan at the top of the staircase: Results of tests 29 through 38 with 3 type B fans. Two fans on the platform were combined with one fan at the top of the staircase. The distance of this latter fan to the exit varied. The tests in which the fan is at a distance of $40 \mathrm{~cm}$ from the door are indicated with the solid black line (tests 29 - 33). The blue dashed line indicates a distance of 90 $\mathrm{cm}$ (tests 34 - 38). The red line indicates the flow rate corresponding to the critical velocity. The distance between the fans on the platform and the stairs is on the horizontal axis.

In a second series of experiments with three type $B$ fans, four different placements for the top fan were compared (see Figure 5) in tests 56 - 59. This was done to decide on the position of the top fan that would be used in the tests with four fans. All the fans had an inclination of $10^{\circ}$. 
The fan at the top of the staircase was placed first on the centre line of the exit, $40 \mathrm{~cm}$ from the door (test 56). The distance was then changed to $90 \mathrm{~cm}$ (test 57). The two final positions were set-ups where the axis of the fan was on the line connecting the centre line of the stairs to the centre of the door. In test 58, the fan was placed close to the exit door (position ' $c$ ' in Figure 5, labeled 'turn close'). In test 59, it was placed close to the stairs, further away from the exit door (position ' $d$ ', labeled 'turn far').

Two fans were positioned on the platform at a distance of $3 \mathrm{~m}$ from the stairs during the four experiments. These two fans were positioned with reference to the centre line of the stairs at $-25 \mathrm{~cm}$ and $+150 \mathrm{~cm}$. The leftmost fan had its axis parallel with the centre line of the stairs while the rightmost fan had its axis oriented towards the centre of the stairs. This meant that it was turned $27^{\circ}$ horizontally. These positions correspond to positions that are likely to be used by firefighters intuitively.

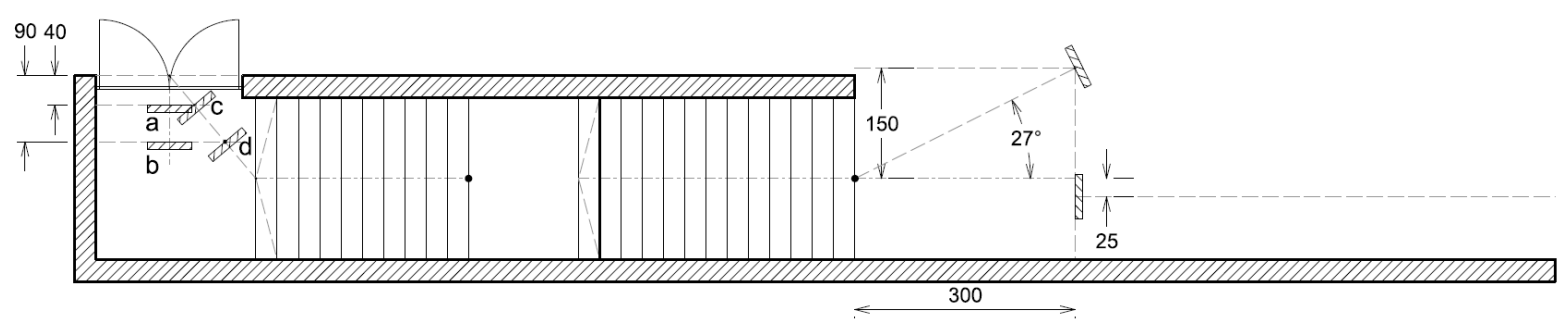

Figure 5 Four different fan positions at the top of the staircase. Position a: $40 \mathrm{~cm}$ from the door during test 56 . Position b: $90 \mathrm{~cm}$ from the door during test 57 . Position c: $40 \mathrm{~cm}$ from the door on the line that connects the centre of the door with the centre of the stairs ('turn close') during test 58. Position d: $90 \mathrm{~cm}$ from the door on the line ('turn far') during test 59 . Two additional fans were placed on the platform.

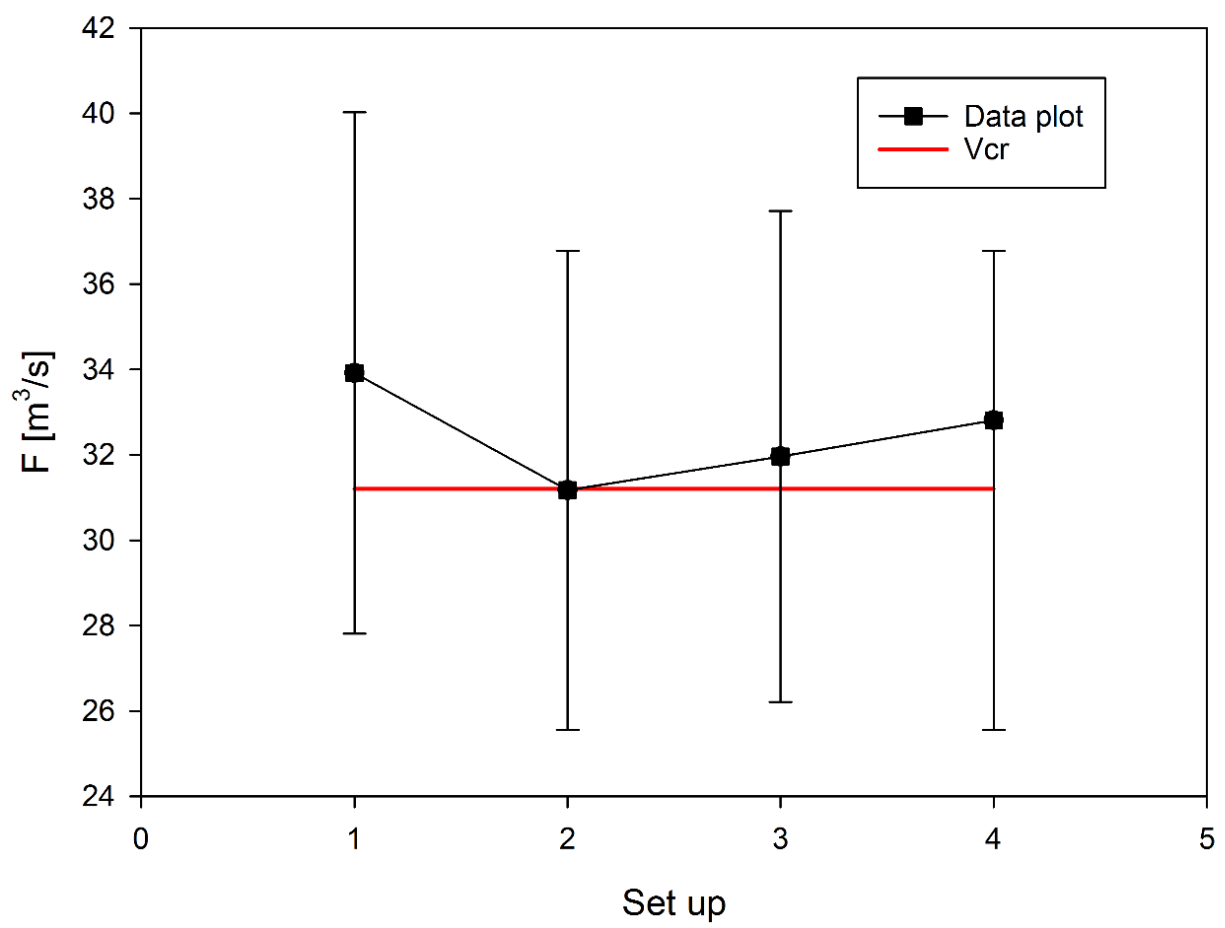

Figure 6 Influence of top position: Comparison of 4 positions at the top of the staircase (tests 56 59): from left to right: $40 \mathrm{~cm}, 90 \mathrm{~cm}$, turn close and turn far. The positions of the fan are found in Figure 5 . The red line indicates the flow rate corresponding to the critical velocity. 
Figure 6 shows that the influence of the top position is very limited. Note that the result for position b $(90 \mathrm{~cm})$ could be an under-estimation, since higher values were obtained with the fans on the platform at $3 \mathrm{~m}$ distance from the stairs in the other series of tests (Figure 4). Since the influence of the top fan was found to be very limited, the choice was made to continue with the 'turn far' position since it corresponds to what firefighters would intuitively use.

\subsection{Four fans vs three fans}

The manufacturer states that a higher effectiveness is achieved when multiple fans are positioned such that there is sufficient space in between them [22]. Though the manufacturer does not precisely define this requirement, it can be assumed that the space limitations of the present set-up render the effectiveness lower than optimum.

Therefore, it was interesting to check whether or not adding a third fan on the platform had any extra benefit. In earlier research [11], two fans were positioned in a $V$ shape. Adding a third fan led to a higher generated flowrate. In order to evaluate this possibility, 16 tests were performed. In 8 tests $(59-62 ; 77 ; 79 ; 81 ; 83)$, two fans on the platform were combined with one fan at the top of the staircase. In the other 8 tests $(72-75 ; 97-$ 100), a third fan was added on the platform. In all the tests, the fan at the top of the staircase was positioned in such a manner that the axis of the fan was on the line connecting the centre of the stairs with the centre of the exit door ('turn far').

In the tests with two fans on the platform, two type B fans were placed as described above $(-25 \mathrm{~cm}$ and $+150 \mathrm{~cm}$ ). The distance to the first step of the stairs was varied from $3 \mathrm{~m}$ to $9 \mathrm{~m}$ with a $2 \mathrm{~m}$ interval. The increasing distance from the stairs leads to a decreasing angle of the rightmost fan from $27^{\circ}(3 \mathrm{~m})$ to $9^{\circ}(9 \mathrm{~m})$, see Figure 9. The fan at the top of the staircase was a type $B$ as well.

In the tests with three fans on the platform, the third type $B$ fan was placed in between the other two fans (see Figure 7). The distance to the centre line was $+67 \mathrm{~cm}$ and the axis of the fan was parallel with the centre line of the stairs. The distance to the first step of the stairs was varied from $3 \mathrm{~m}$ to $9 \mathrm{~m}$

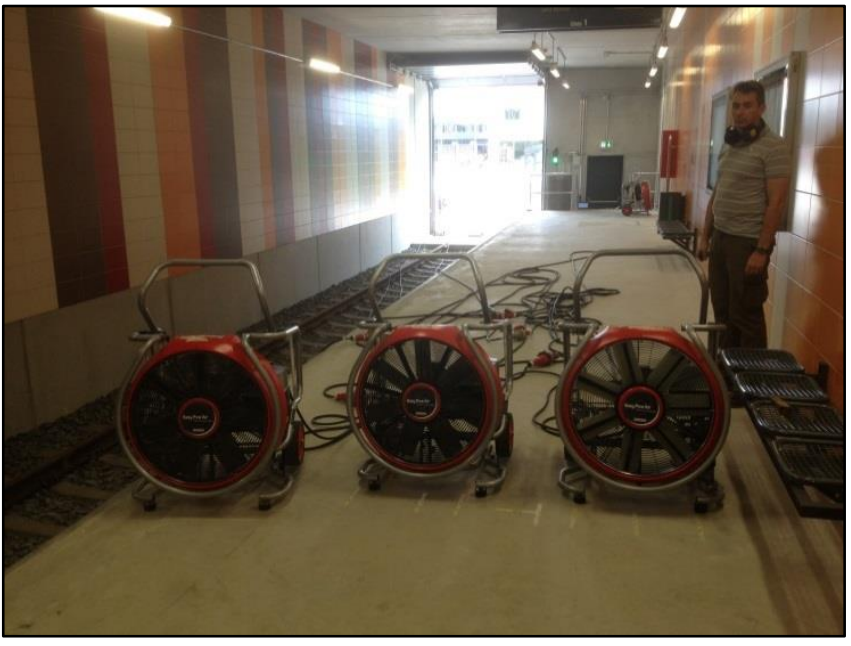

Figure 7 Three fans placed on the platform in the Frankfurt subway building. The fans are positioned with reference to the centre line of the stairs. From right to left: $-25 \mathrm{~cm},+67 \mathrm{~cm}$ and $+150 \mathrm{~cm}$. The stairs are behind the photographer. The fan on the right in the picture is addressed as 'left' in the text and vice versa. with a $2 \mathrm{~m}$ interval. A type $\mathrm{A}$ fan was placed at the top of the staircase.

In the first series (tests $59-62 ; 72-75$ ), the angle of inclination for all the fans was $10^{\circ}$. In the second series (tests $77 ; 79 ; 81 ; 83 ; 97-100$ ), the angle of the fans on the platform was $18^{\circ}$, while the inclination of the type $A$ fan at the exit remained $10^{\circ}$. 


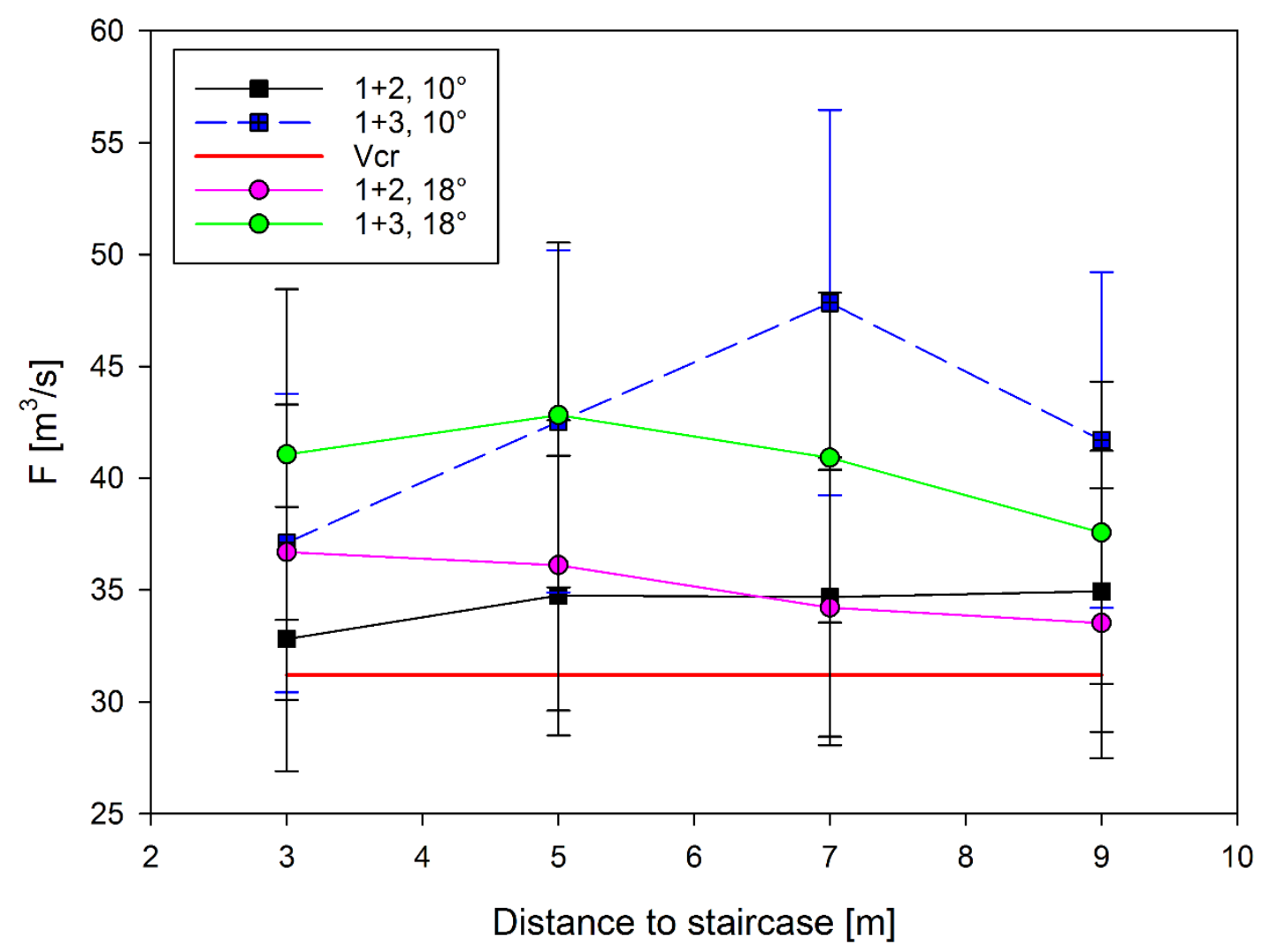

Figure 8 Three versus four fans: Comparison of placements with 3 and 4 fans. The squares refer to fans with an inclination of $10^{\circ}$, the circles to an inclination of $18^{\circ}$. Line types: solid purple: 2 fans on the platform with an $18^{\circ}$ inclination (tests $77 ; 79 ; 81 ; 83$ ); solid black: 2 fans on the platform with an $10^{\circ}$ inclination (tests 59-62); blue dashed: 3 fans on the platform with a $10^{\circ}$ inclination (tests 72-75); solid green: 3 fans on the platform with an $18^{\circ}$ inclination (tests 97-100). The red line indicates the flow rate corresponding to the critical velocity.

The following observations are made. First of all, four fans always generate higher flow rates than three fans, as expected. However, the increase is much less than $50 \%$ (increasing from two to three fans on the platform), due to restrictions in the available width. The width of the platform does not allow to create more space between the fans (see Figure 7). The manufacturer indicates that the generated flow rate decreases compared to the nominal flow when the fans are too close to each other [22]. Second, the flow rate is higher with an inclination angle of $18^{\circ}$ if the fans are placed at a distance of less than $5 \mathrm{~m}$ from the stairs, compared to $10^{\circ}$ inclination angle. The reason is probably that the flow is much better aligned with the stairs at $18^{\circ}$ inclination angle, reducing the pressure loss for the flow. The opposite is observed for larger distances ( $7 \mathrm{~m}$ and $9 \mathrm{~m}$ ), because now the $10^{\circ}$ inclination angle provides better alignment with the corridor (less impingement of the cone airflow onto the ceiling), thus reducing the pressure losses for the flow in that region. Third, a reduction in flow rate is observed when the distance is increased from $7 \mathrm{~m}$ to $9 \mathrm{~m}$, definitely when four fans are used. This is due to a reduction in effectiveness in using the opening area towards the staircase, as already mentioned above. Fourth, all of the experiments with three and four fans generate a flow exceeding the critical velocity. 


\subsection{Position of the fans ( 4 fans)}

29 tests were performed with four fans in the building. In each experiment, one type $A$ fan was positioned at the exit of the subway building on the upper floor. This fan was always placed in the 'turn far' position. In 12 of these experiments one type $B$ fan was placed on the landing of the staircase (tests $68-71 ; 85-92$ ). This fan was always positioned on the centre line of the landing with the back of the fan at the edge of the landing (see Figure 9). The other two type $B$ fans were placed on the platform at four different distances from the staircase: $3,5,7$, and $9 \mathrm{~m}$. The two fans on the platform were positioned with reference to the centre line of the stairs $(-25 \mathrm{~cm}$ and $+150 \mathrm{~cm})$. The fan at $-25 \mathrm{~cm}$ had its axis parallel to the centre line of the stairs while the fan at $+150 \mathrm{~cm}$ had its axis oriented towards the centre of the stairs. This meant that it was turned $9-27^{\circ}$ horizontally, depending on the distance from the stairs. All fans had a vertical inclination of $10^{\circ}$ during tests $68-71$ and tests $85-88$. The vertical inclination of the fans on the platform was $18^{\circ}$ during tests 89 to 92.

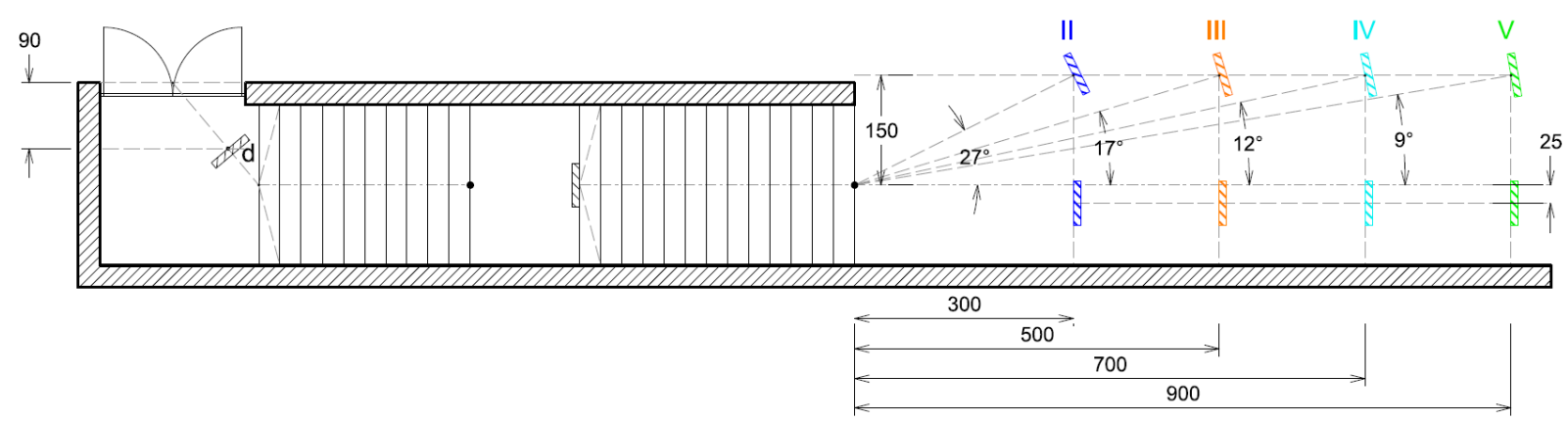

Figure 9 The set-up of experiments 68 to 71 and 85-88. The type A fan upstairs was in the 'turn far' position. On the landing, there was 1 type $B$ fan. The two fans on the platform were placed at 4 different distances. The inclination of the fans was $10^{\circ}$. In experiments 89-92, the same set-up was used but the inclination of the fans on the landing and platform was changed to $18^{\circ}$.

In tests 72 to 75 , there was no fan on the landing. The fourth fan (type B) was also placed on the platform at a distance of $+67 \mathrm{~cm}$ with reference to the centre of the stairs.

The results in Figure 10 show that the set-ups with three fans on the platform and one at the building exit (tests 72 - 75) consistently generate a higher flow rate than the set-ups with two fans on the platform, one on the landing and one at the building exit (tests 68 71). The extra flow generated varies from 9 to $23 \%$. There seems to be an optimum at 7 $\mathrm{m}$ distance from the stairs, regardless of the set-up. Presumably this is due to the more ideal use of the opening towards the staircase (compared to the $9 \mathrm{~m}$ distance), in combination with a good alignment of the flow with the stairs (compared to the $3 \mathrm{~m}$ and 5 $\mathrm{m}$ distances), as explained above. The results also show that the measured flows exceed the value needed for the critical velocity. 


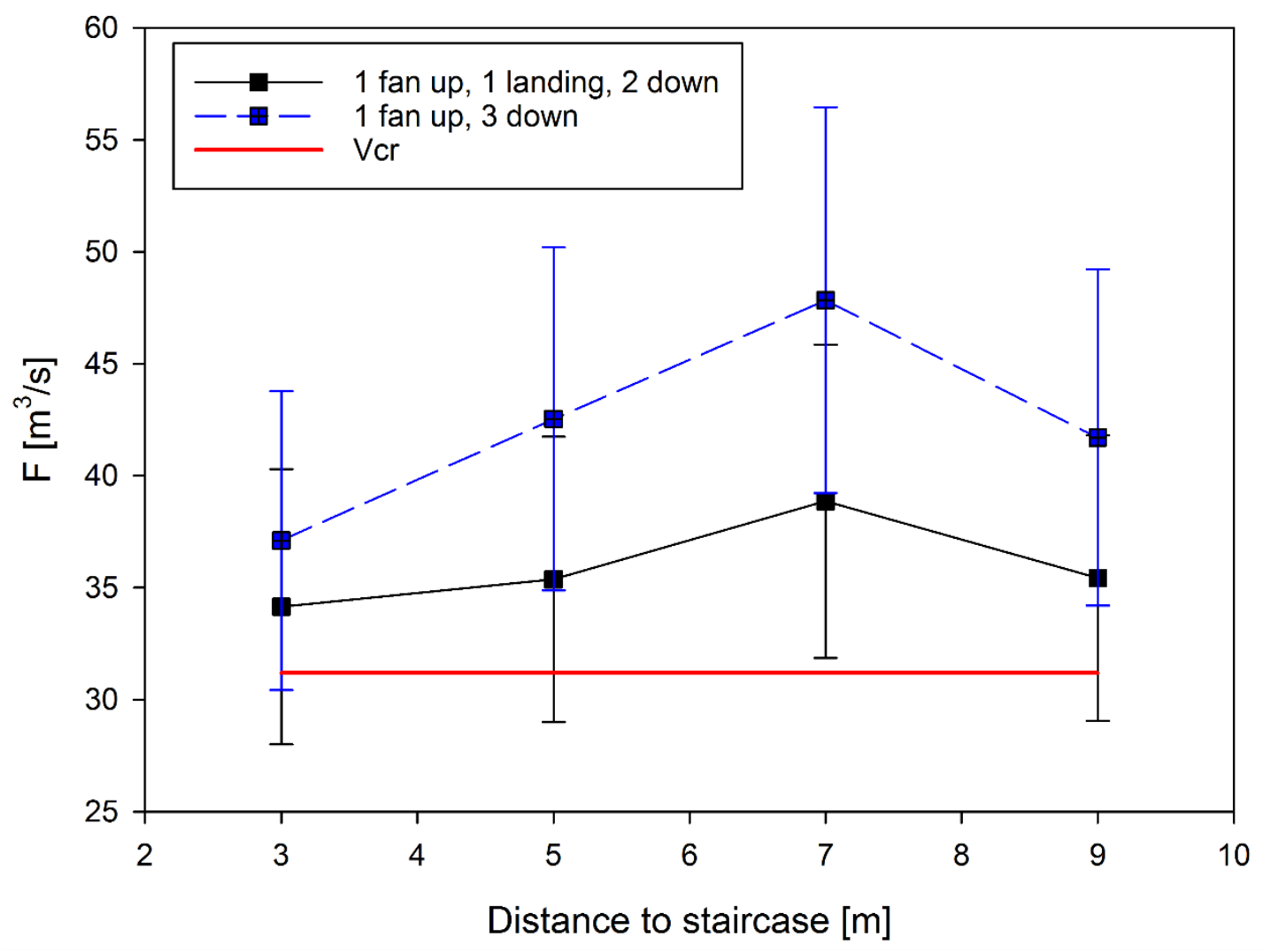

Figure 10 Flow generated by four fans: Comparison of two different types of set ups. One type A fan was placed at the exit door of the building. Two type B fans were placed on the platform. The third type B fan was placed on the landing in test 68-71 (solid line) or on the platform between the two other fans in test 72-75 (dashed line). The red line indicates the flow rate corresponding with the critical velocity.

\subsection{The vertical inclination of the fans}

The impact of the inclination angle $\left(10^{\circ}\right.$ vs. $\left.18^{\circ}\right)$ has been examined during 22 tests. The results of three series of tests are shown in Figure 11. In all tests, the fan upstairs was in position $d$ ('turn far') in Figure 9. The fan upstairs always kept an inclination angle of $10^{\circ}$. In the tests with three fans, this was a type $B$ fan. In the tests with four fans, it was a type A fan. In the first series of tests (59-66), indicated " $1+2$ " in Figure 11, two type B fans were placed on the platform. The two fans were placed with reference to the centre line of the stairs $(-25 \mathrm{~cm}$ and $+150 \mathrm{~cm})$ The distance to the stairs for the two fans on the platform varied from $3 \mathrm{~m}$ to $9 \mathrm{~m}$ with an interval of $2 \mathrm{~m}$. During tests 59 through 62, the fans on the platform had an inclination of $10^{\circ}$. During the tests 63 through 66, this angle was adjusted to $18^{\circ}$. In a second series of tests (93-100), indicated " $1+3^{\prime \prime}$ in Figure 11 , a third fan was placed on the platform as described above. The first four of the series had fans on the platform with an inclination of $10^{\circ}$. During the last four, the inclination was $18^{\circ}$. In a third series of tests (85-92), indicated " $1+1+2$ " in Figure 11, the third fan was placed on the landing instead of on the platform as described above. Again, the first four tests worked with an inclination of $10^{\circ}$ while the last four had an inclination of $18^{\circ}$. 


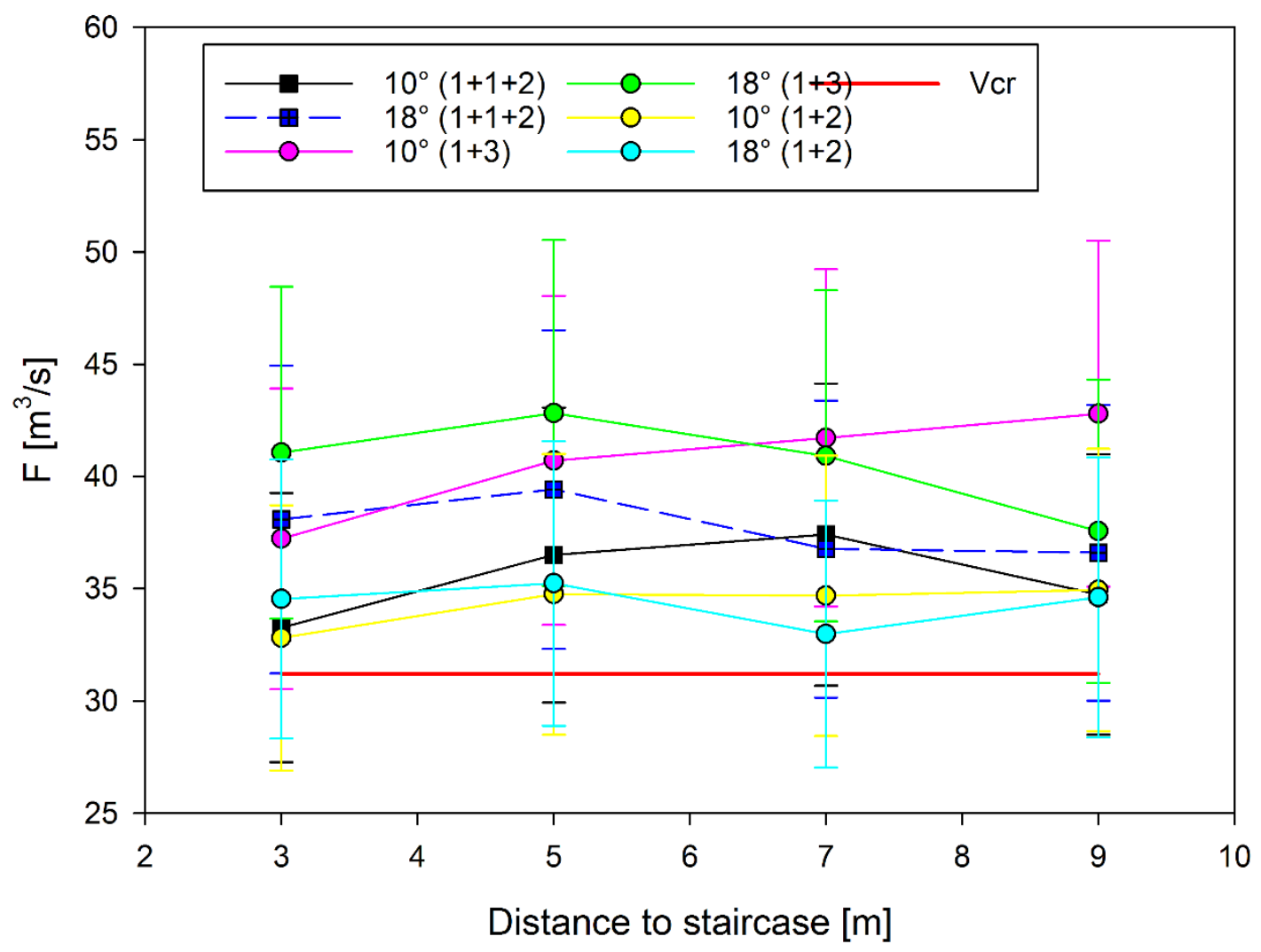

Figure 11 Inclination angle: $10^{\circ}$ versus $18^{\circ}$ : Comparison of 3 series of tests with an inclination of $10^{\circ}$ to an inclination of $18^{\circ}$. Line types: solid green: 1 fan on top, 3 fans on the platform $(1+3) 18^{\circ}$; solid purple: $(1+3) 10^{\circ}$; dashed blue: 1 fan on top, 1 on the landing, 2 on the platform $(1+1+2)$ $18^{\circ}$; solid black: $(1+1+2) 10^{\circ}$; solid light blue: 1 fan on top, 2 on the landing $(1+2) 18^{\circ}$; solid yellow: $(1+2) 10^{\circ}$. The red line indicates the flow rate corresponding to the critical velocity.

Figure 11 confirms that the set-ups with inclination $18^{\circ}$ generate a higher flow than those with $10^{\circ}$ when they were placed closer to the staircase (up until a distance of $5 \mathrm{~m}$ ). The optimum distance for fans with inclination $18^{\circ}$ seemed to be $5 \mathrm{~m}$. This is logical because the $18^{\circ}$ tilted fan at a distance of $5 \mathrm{~m}$ from the stairs will generate a flow directed to a height of $1.9 \mathrm{~m}$. This is more or less the middle of the height of the opening towards the staircase. The second reason why the closer position leads to an increased flow is that the flow from the fan has less distance to open up. The closer to the opening (towards the staircase), the more flow of the fan that enters the staircase. The height of the staircase opening is limited to $3.73 \mathrm{~m}$. The spread rate of the fans is $15^{\circ}$. The diameter of the flow of the fans will $3.56 \mathrm{~m}$ at a distance of $5 \mathrm{~m}$. This diameter becomes $4.75 \mathrm{~m}$ at a distance of $7 \mathrm{~m}$. This explains why the effectiveness drops at a distance of $7 \mathrm{~m}$ and higher. Figure 11 confirms as well that all the positions generate a flow rate exceeding what is needed for the critical velocity, regardless of whether the inclination is $10^{\circ}$ or $18^{\circ}$.

\section{Discussion}

When the experiments were prepared, the choice was made to measure the velocity at the inlet opening, i.e. the entrance for the subway cars at the bottom floor. Another option could have been to measure the velocity at the outlet opening. In a real subway station, the inlet opening would be the connection with the tunnel. In this experimental campaign, 
the generated velocities were compared to the critical velocity that would be necessary for a virtual fire in a virtual tunnel attached to the station. Therefore the velocity measurements were performed at the inlet opening. A second reason for this location is that the flow at the outlet was not uniform at all. A fan was placed at the top of the staircase blowing towards the outlet. It is harder to characterize a highly non-uniform flow than the more uniform flow at the inlet.

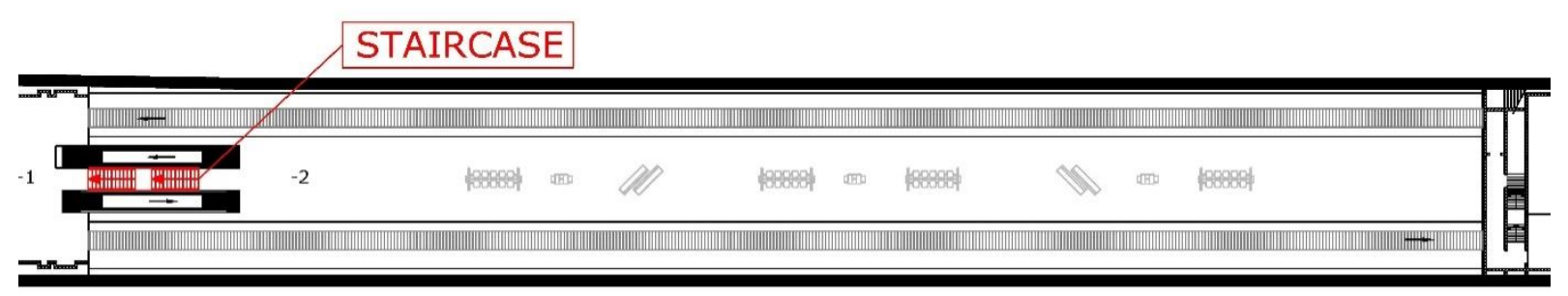

Figure 12 Floor plan of a subway station with two tracks and one, central platform. The staircase is on the left-side of the floorplan. This floor plan is shown for illustrative purposes only.

The geometry of the building that was used for the tests is very simple because it has been constructed for training firefighters. In a real subway station, the situation can be very different. The platform will be wider, allowing for more fans to be positioned (e.g., see Figure 12). There may be multiple platforms and multiple staircases. In a subway station with two tracks and two platforms (one on each side of the tracks) fans can be positioned on both platforms, using both of the staircases (e.g., see Figure 13).

In a subway station with one staircase (e.g., see Figure 12), the fans on the platform will create a flow towards the staircase. If the flow in the tunnel exceeds the critical velocity, there will be no backlayering in the tunnel in the case of a train fire in the tunnel. In the case of a fire in the station, the backlayering distance should be less than $15 \mathrm{~m}$. This will allow firefighters to approach the fire from the adjacent subway station. By doing so they will attack the fire from a smoke-free environment which is an important advantage from a tactical point of view. The same principle is applicable for subway stations where multiple staircases are located close to one another.

A disadvantage of this tactic is that the staircases that are used as exhaust are no longer usable for civilians as escape route as soon as the ventilation has started. On the other hand, NFPA 130 prescribes a platform evacuation time of less than four minutes. Subway stations should be designed such that the evacuation time to a point of safety is less than six minutes [12]. In practice, the fire service will typically only arrive after more than four minutes. After arrival, they have to set up the fans. This will take some more time. Most of the civilians present should have evacuated before the fans are started. The fact that the staircase is used as the outlet should not endanger them. The civilians that are still present in the subway station at that moment will need to be rescued by the fire service, regardless of the use of fans. The officer in charge will have to decide which part of the operation (ventilation or rescue) needs to be carried out first. In many cases, ventilation can serve as a form of rescue in that, when performed correctly, it should create a survivable atmosphere for victims. It's a question of removing the problem or removing the victim: both can be of significant value, depending on the situation. 


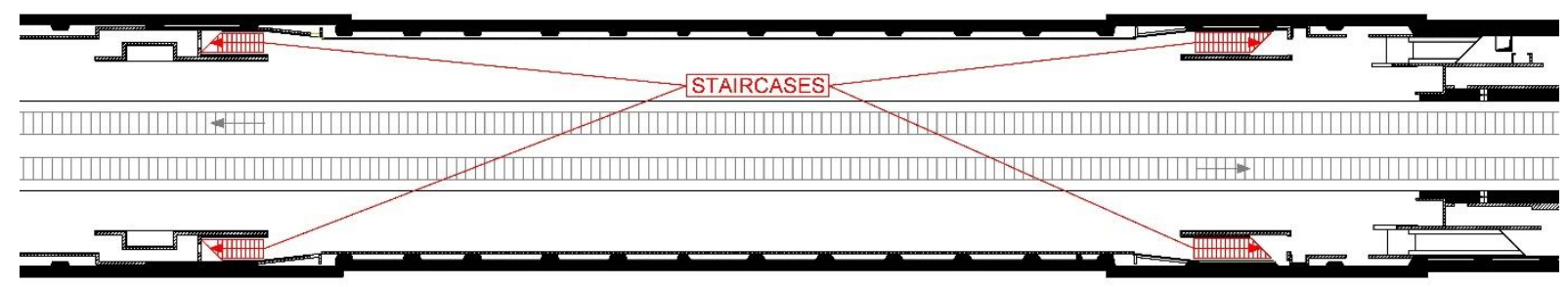

Figure 13 Floor plan of a longer subway station. The station has two tracks and two platforms. The main staircases are at the end of each platform. The staircases are indicated with the green arrows. The floorplan is shown for illustrative purposes only.

In long subway stations (e.g., see Figure 13), there will be two or more stairs per platform leading to the ground floor. Often, the lay-out of the station is such that the two blocks of stairs are separated: one at each end of the platform. This leads to new tactical possibilities. If there is a subway car burning in the station, firefighters could use fans to generate a flow that uses the stairs at one end of the platform as the outlet. The backlayering distance should be less than $15 \mathrm{~m}$. The staircases at the other end of the subway station and the portal of the tunnel will be used as an inlet for make-up air.

This means that the stairs at the other end of the station can be used in this case as a smoke-free approach route to the fire in the subway station. In this type of station, the smoke-free stairs can be used continuously for evacuation of civilians. This means that during the ventilation, other firefighters can assist civilians who need more time to escape (elderly people, children) or evacuate people they rescued (collapsed people).

The generated flow came through the entrance opening for railway cars in the training building. In a subway network, a tunnel would be attached to the station. The presence of this tunnel will lead to pressure losses. Moreover, the ambient wind conditions at the tunnel portals may have a significant influence on the generated flow. In this work, the experimental procedure cancelled out the effect of the wind. For every experiment, the prevailing wind was time-averaged and used as a baseline for the determination of the generated flow. Future work could consist of the study of the impact of the tunnel network on the generated flow. This should take into account the wind effect on tunnel portals.

This paper is focussed on the flow rates generated by the fans. In reality it will be of utmost importance to put the fans in the correct position to achieve an improvement of the situation. This needs to be well-coordinated and planned for by the fire service. Therefore some guidance is given here. When the fire service wants to generate a flow where a certain staircase is used as an outlet while at the same time another staircase is used as an inlet, the fans will need to be in a specific position. It is nearly impossible to make decisions on the position of the fans during the incident itself. Fire services should make a detailed pre-plan for every subway station in their jurisdiction. The stairways used as an inlet and used as an outlet should be indicated onto the plan as well as the number, type and position of the fans to be used. The position of the fan should describe the inclination, the separation between fans and the distance to the staircase to obtain maximum efficiency. Moreover, the start of the ventilation should be well-coordinated with the attack crews as it can be disastrous if the smoke is pushed up the wrong staircase. Firefighters performing the attack on the fire should be aware of the fact that the ventilation will alter the flow of the smoke and heat in their working environment. 


\section{Conclusions}

The generated flow rates in the experiments with four fans (one upstairs and three on the platform) varied from $37.2 \mathrm{~m}^{3} / \mathrm{s}$ to $47.8 \mathrm{~m}^{3} / \mathrm{s}$. This represents only 36 to $47 \%$ of the rating in open air, as given by the manufacturer. When the third fan on the platform was removed, the generated flow rates varied between $32.8 \mathrm{~m}^{3} / \mathrm{s}$ and $36.8 \mathrm{~m}^{3} / \mathrm{s}$. This represents 45 to $50 \%$ of the rating in open air. This shows that an extra fan on the platform has added value. It also shows that the effectiveness per fan drops when the fans are placed too close to each other. This confirms the general guidance of the manufacturer.

There is an optimum distance from the stairs for the inclined fans. This confirms the findings by Ezekoye et al [10]. The inclination of the fan is an important parameter. Fans with an inclination of $10^{\circ}$ reach an optimum flow rate when they are positioned at $7 \mathrm{~m}$ from the staircase. This becomes $5 \mathrm{~m}$ when the inclination is set at $18^{\circ}$. The location of the optimum depends on the inclination of the fan and the geometry of the opening. The flow has to be aimed towards the centre of the height of the opening. A second parameter to be taken into account is that the flow of the fan becomes wider with an increasing distance from the fan. When the flow becomes wider than the opening, the effectiveness will decrease.

The top position does not have a strong influence. The variation between the four tested positions at the top was only $9 \%$. Firefighters can position the fan in an intuitive position in order to obtain a good result.

The experiments reveal that three fans on the platform generate a better result than two fans on the platform and one on the landing. The inclination of the fans on the platform is important. The flow should be aimed towards the centre of the stairs leading to the floor above. The fan blowing towards the exit at the ground floor can be positioned intuitively by the firefighters.

The first criterion for success was met (i.e., no smoke backlayering in the tunnel) for a situation where only one tunnel arrives in the station. All positions with four fans achieved a flow with a velocity superior to the critical velocity for a hypothetical fire in the tunnel. Most positions with three fans achieved this as well. In the training building, simulating a subway station, the fans were capable of realizing a flow beyond the critical velocity for a small tunnel. This means that the tested fans should be capable of preventing backlayering in a tunnel that would be attached to such an underground station. The PPV fans could be used successfully for tactical ventilation in a small underground tunnel.

It has to be pointed out that the training building is small compared to a real subway station. This will lead to higher flow rate demands to achieve the critical velocity in real subway stations. On the other hand, platforms will be wider in real subway stations. On a wider platform, the fans can be positioned with more space between them. When the distance between the fans is limited, they do not achieve their full potential. When the distance between fans is increased, this will enable the fans to generate higher flows. Moreover, often two or more platforms are present in subway stations (see Figure 12 and Figure 13). This would allow doubling of the number of fans that could be used, which would lead again to higher velocities. 
The second criterion for success was also met for six of the tests $(73-75,95,96,98)$ presented in this study. The ventilation in the subway station will be successful as long as the generated flow rate is $41.2 \mathrm{~m}^{3} / \mathrm{s}$ or higher, regardless of the heat release rate of the fire. This is potentially very important for firefighters because they can attack the fire, approaching it from a smoke-free environment.

The other 42 tests achieved a flow rate lower than $41.2 \mathrm{~m}^{3} / \mathrm{s}$. The heat release rate corresponding to a backlayering distance of $15 \mathrm{~m}$ in the subway building for the given velocity has been calculated for these tests. The maximum allowable heat release rate varies from 2.41 MW to 7.12 MW. These heat release rates are lower than the heat release rate of a subway car [20]. Therefore, the second criterion of success is only met for low enough heat release rates.

\section{Acknowledgements}

This paper is a summary of the thesis of Karel Lambert [20], performed in the context of the International Master of science in Fire Safety Engineering (IMFSE) at the universities of Ghent, Lund and Edinburgh. The first author strongly acknowledges the financial support from EACEA during his studies in IMFSE, the material support of the Brussels fire department, the Frankfurt Fire Department and Ghent University. The authors also acknowledge Associate Professor Stefan Svensson (Lund University) for their valuable comments during the research. Finally, the authors thank Nathalie Van Moorter for the illustrations in this paper.

\section{References}

[1] Svensson S. (2000) Fire Ventilation, Swedish Rescue Services Agency

[2] Ziesler PS, Gunnerson FS, Williams SK (1994) Advances in positive pressure ventilation: Live fire tests and laboratory simulation, Fire Technology, vol 30, 269277

[3] Vaari J, Hietaniemi J (2000) Smoke ventilation in operational fire fighting. Part 2: multi-story buildings. VTT publications 419 , Technical research centre of Finland

[4] Svensson S (2001) Experimental study of fire ventilation during fire fighting operations, Fire Technology, vol 37, 69-85

[5] Le Corré $F$ (2001) Ventilation dans les incendies appliqué au métro Parisien, ENSAM Paris, France

[6] Lougheed GD, McBride PJ, Carpenter DW (2002) Positive pressure ventilation for high-rise buildings. National Research Council Canada

[7] Ezekoye OA, Hal CH, Nicks R (2003) Positive pressure ventilation attack for heat transport in a house fire. In: The 6th ASME-JSME thermal engineering joint conference, $16^{\text {th }}-20^{\text {th }}$ March

[8] Ezekoye et al. (2005) Effects of PPV attack on thermal conditions in a compartment downstream of a fire. Fire Technology, vol 41, 193-208

[9] Kerber S, Walton W (2005) Effect of positive pressure ventilation on a room fire, NISTIR 7213, Gaithersburg, MD, USA: National Institute of Standards and Technology

[10] Ezekoye OA, Svensson S, Nicks R (2007) Investigating positive pressure ventilation. In: Proceedings of 11 th international fire science $\&$ engineering 
conference (Interflam '07), 3rd-5th September, Interscience communications, London

[11] Lambert K, Merci B (2014) Experimental Study on the Use of Positive Pressure Ventilation for Fire Service Interventions in Buildings with Staircases, Fire Technology, vol 50, 1517-1534

[12] NFPA 130 (2010) Standard for fixed guideway transit and passenger rail systems

[13] McCaffrey BJ, Heskestad G (1976) A robust bidirectional low-velocity probe for flame and fire application, Combustion and flame, Vol 26, No 1, 125-127

[14] Oka Y, Atkinson G (1995) Control of smoke flow in tunnel fires, Fire safety journal, Vol 25, 305-322

[15] Wu Y, Bakar M (2000) Control of smoke flow in tunnel fires using longitudinal ventilation systems - a study of the critical velocity, Fire safety journal, Vol 35, 363-390

[16] Fathi T (2010) New perspectives on the critical velocity for smoke control, In proceedings: 4th international symposium on tunnel safety and security, Frankfurt am Main, Germany

[17] Li Y (2010) Study of critical velocity and backlayering length in longitudinally ventilated tunnel fires, Fire safety journal, Vol 45, 361-370

[18] NBN S21-208-2 (2010) Fire protection in buildings - Design and calculation of smoke and heat extraction installations - Part 2: Covered car park buildings

[19] Ingason $\mathrm{H}$ (2005) Fire dynamics in tunnels - In: the handbook of tunnel fire safety, 2nd edition, by Carvel R, Beard A, chapter 13, p 273-307

[20] Bartlett N (2012) Optimization of smoke control systems in underground subway stations, IMFSE dissertation, Ghent University

[21] Lambert K (2014) Positive pressure ventilation in underground systems - an experimental and modelling study, IMFSE dissertation, School of Engineering, The University of Edinburgh

[22] Leader Group, www.leader-group.eu, Octeville-sur-mer, France

[23] Willi J, Madrzykowski D, Weinschenk C (2016) NIST Technical note 1938: Impact of hose streams on air flows inside a structure

[24] Bryant RA (2009) A comparison of gas velocity measurements in a full-scale enclosure fire, Fire Safety Journal, Vol 44, 793-800 